\title{
Controversy
}

\section{High or low oxygen saturation for the preterm baby}

The observational study by Tin $e t a l^{1}$ of outcome related to oxygen saturation in infants of less than 28 weeks gestation from a number of disparate units in the Northern Region shows results that are interesting, but only from the point of hypothesis generation.

Monitoring of oxygen saturation is simple but not without problems. ${ }^{23}$ Setting aside whether preterm infants requiring additional oxygen should be managed by monitoring oxygen saturation or oxygen partial pressure, does this study have any implications for management of such infants in the future? Is there any other corroborative evidence that the outcome of infants managed at lower saturations do better in terms of neurodevelopmental, respiratory, growth, or visual outcome?

The STOP-ROP study was designed to test the hypothesis that supplemental oxygen would reduce progression of retinopathy of prematurity (ROP). Infants with prethreshold ROP were randomised to either high (96-99\%) or low (89-94\%) saturation groups. There were no significant differences in the visual outcomes. Supplemental oxygen, however, increased the risk of adverse respiratory events including pneumonia and chronic lung disease with significant need for extra oxygen, diuretic therapy, and hospitalisation at 3 months corrected age. There was no difference in growth or neuromotor development. ${ }^{4}$ The respiratory morbidity in this study was not the primary study outcome and we must await the "Benefits of Oxygen Saturation Targeting Trial" from Australia to confirm or refute these findings (D Henderson-Smart, personal communication).

More pertinent may be work in an animal model of ROP indicating that management in lower oxygen (reducing the mean partial pressure of oxygen by $2 \mathrm{kPa}$ to the lower end of the "safe" range) reduces the incidence and severity of ROP. ${ }^{5}$ Preliminary data from this model also show that apoptotic proteins (compared with antiapoptotic proteins) in the brain are increased with higher oxygen. ${ }^{6}$

Preterm babies must be given adequate oxygen, but possibly our reference to well term infants is inappropriateinfants with relatively low saturations because of cyanotic heart disease are not automatically compromised with regard to either growth or neurodevelopment.

Child Life and Health

NEIL MCINTOSH

University of Edinburgh

Edinburgh EH9 1 UW, Scotland

Neil.Mcintosh@ed.ac.uk

1 Tin W, Milligan DWA, Pennefather P, et al. Pulse oximetry, severe retinopathy, and outcome at one year in babies of less than 28 weeks gestation. Arch Dis Child Fetal Neonatal Ed 2001;84;F106-10.

2 Gibson LY. Pulse oximeter in the neonatal intensive care unit: a co relational analysis Pediatric Nursing 1996;21:511-15.

3 Grieve SH, McIntosh N, Laing IA. Comparison of two different pulse oximeters in monitoring preterm infants. Crit Care Med 1997;25:2051-4.

4 The STOP-ROP Multicenter Study Group. Supplemental therapeutic oxygen for prethreshold ritin for prethreshold retinopathy of prematurity (STOP-ROP), a rand
controlled trial. I. Primary outcomes. Pediatrics 2000;105:295-310.

$5 \mathrm{McColm}$ J, Cunningham S, Wade J, et al. Relative contribution of hypoxia in the development of retinopathy in rats. Pediatr Res. In press.

6 Sedowofia K, McColm J, Fleck B, et al. Oxygen variability and the developing rat brain. Pediatr Res. In press.

Neonatology has often re-evaluated its basic tenets, either by force of evidence or voluntarily. No issue carries such scars as the soul searching that accompanied the first discovery that use of unrestricted oxygen was associated with retrolental fibroplasia. ${ }^{1}$ The subsequent reduction in the use of oxygen has been estimated to have caused 16 children to die or survive with severe disability for every child whose sight was saved. ${ }^{2}$

Memories are short, and over the last two decades the introduction of simple non-invasive monitoring of oxygen saturation has saved many infants from repeated arterial puncture, transfusion, and the complications of both techniques, but with little attention to the well known and very poor correlation between $\mathrm{SaO}_{2}$ and $\mathrm{PaO}_{2}$. In vivo correlation studies would indicate that to keep $\mathrm{PaO}_{2}$ between 7 and 10 $\mathrm{kPa}(50-70 \mathrm{~mm} \mathrm{Hg})$, oxygen saturation levels between 85 and $94 \%$ need to be accepted, but that at $94 \%$ saturation $\mathrm{PaO}_{2}$ may vary from 9 to $17 \mathrm{kPa}{ }^{3}$

The paper by Tin and colleagues forces us to look again at what we are doing in terms of oxygen monitoring; it would appear that using lower settings for alarms $\left(\mathrm{SaO}_{2}\right.$ 70-90\%) may have significant benefits for children in terms of less respiratory support, less weight loss, and, most notably, lower rates of serious retinopathy. These differences are so striking that the authors suggest that a randomised trial may be necessary-is this so?

There are difficulties with these data, in that in essence they are comparing the whole spectrum of care in different centres (with one exception) categorised by saturation monitoring policy. There are no direct observations nor do the authors attempt to define correlations between the monitors and blood gases. Furthermore, the actual levels measured are essentially conjecture on the part of the interviewed staff, and it is acknowledged that a different style of care pertained in the units practising monitoring in the lowest range. The authors claim that the higher saturation range is an attempt to keep saturation at a normal "physiological" level, something impossible to determine in an extremely preterm infant.

The rates of retinopathy in the high level monitoring group also seem rather high for UK units. In the Trent study, before the availability of treatment, $17.7 \%$ of infants of 27 weeks or less had grade 3 or worse. ${ }^{4}$ In the EPICure study (a cohort of babies of 25 completed weeks or less born in 1995 in the United Kingdom and Ireland, who have the very highest risk of retinopathy), the rate of treated ROP was only $14.5 \%,{ }^{5}$ almost half the rate in the highest risk group in Tin's study without the inclusion of 26 and 27 week infants. This value is inside the $95 \%$ confidence interval of the three lower level monitoring groups. Does some other factor account for these differences, or are the rest of us getting it "more right"?

What about a randomised trial? It should be easy enough with only around 125 infants required per arm (95\% power). In vivo correlation studies indicate that allowing saturation levels to climb to $98 \%$ is likely to result in $\mathrm{PaO}_{2}$ levels that are much too high, as judged by recommendations based around $\mathrm{PaO}_{2}$ measures (50-80 mm Hg). ${ }^{6}$ Surely this should not be considered good practice? If I was asked to review such a project I would be critical of the high saturation arm; after all we do not simply wish to rediscover the issues dealt with in the 1950s. Five hundred infants per group would be needed to show a reduction from $15 \%$ to $6 \%$; seeing a trial such as this through to completion would be very challenging.

New technology is coming to our assistance, at least in the first few days after birth, with new indwelling continuously reading probes giving us access to direct $\mathrm{PaO}_{2}$ levels. ${ }^{7}$ Many of 
us have not stopped using the umbilical oxygen sensors that were the mainstay of care 20 years ago and the reliability of which seems to be now much improved. Transcutaneous monitoring is effective and at least offers detection of rapid swings in $\mathrm{CO}_{2}$ tensions which may be of harm to the developing brain. Closer monitoring of $\mathrm{PaO}_{2}$ is therefore possible.

Back to basics: thinking about correlations between arterial and saturation measures and what one is trying to achieve may be better approaches than a randomised trial which places one arm at potentially great risk.

\section{NEIL MARLOW}

Academic Division of Child Health, Level E, East Block Queen's Medical Centre, Nottingham NG7 2UH, UK Neil.Marlow@Nottingham.ac.uk
1 Terry TL. Extreme prematurity and fibroblastic overgrowth of persistant vascular sheath behind each crystalline lens. I. Preliminary report. $A m \mathcal{F}$ Ophthalmol 1942;25:203-4.

2 Cross KW. Cost of preventing retrolental fibroplasia? Lancet 1973; ii(7835): $954-6$.

3 Wasunna A, Whitelaw AGL. Pulse oximetry in preterm infants. Arch Dis Child 1987;62:957-1.

$4 \mathrm{Ng}$ YK, Fielder AR, Shaw DE, Levene MI. Epidemiology of retinopathy of prematurity. Lancet 1988;ii(8622):1235-8.

5 Costeloe K, Hennessey E, Gibson AT, et al. The EPICure study: outcomes to discharge from hospital for infants born at the threshold of viability. Pediatrics 2000;106:659-71.

6 American Academy of Pediatrics and American College of Obstetricians and Gynaecologists. Guidelines for perinatal care. 2nd edn. American Academy of Pediatrics and American College of Obstetricians and Gynaecologists, 1988:247.

7 Morgan C, Newell SJ, Ducker DA, et al. Continuous neonatal blood gas monitoring using a multiparameter intra-arterial sensor. Arch Dis Child Fetal Neonatal Ed 1999;80:F93-8.

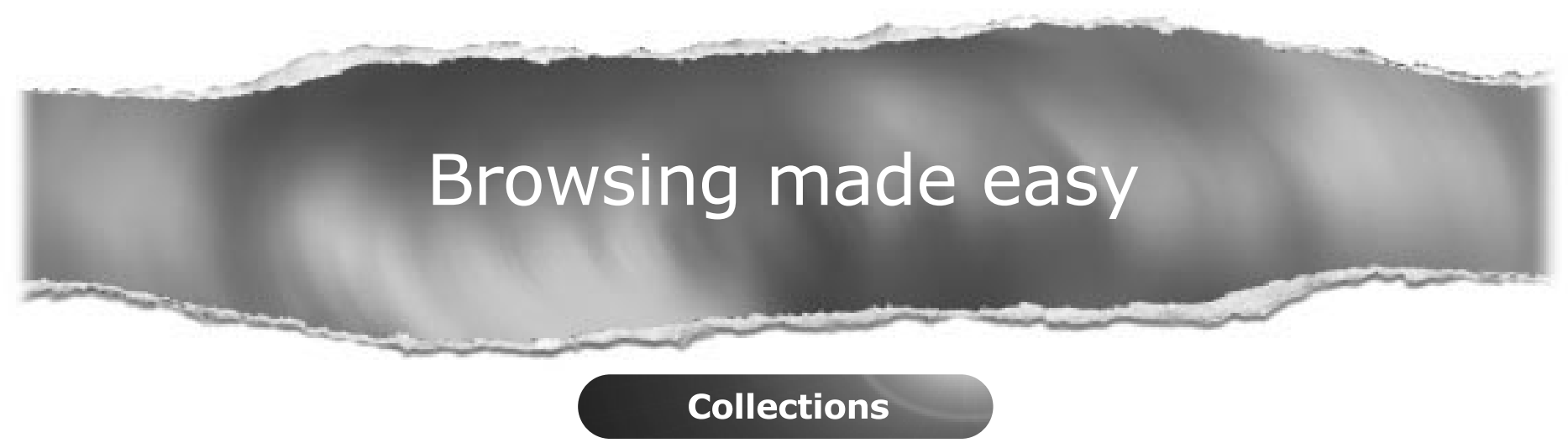

With a single click Collections allows you to find all articles that have been published in your chosen subject. Select from over 200 clinical and non-clinical topic collections and/or cross search other specialist journals, the BMJ and Cochrane Reviews

www.archdischild.com 